\title{
FUSÃO DE IMAGENS POR IHS PARA MELHORAR A IDENTIFICAÇÃO DE USO DO SOLO EM ELEMENTOS AMOSTRAIS ${ }^{1}$
}

\section{MARCOS ADAMI ${ }^{2}$, FLAVIO DEPPE ${ }^{3}$, RODRIGO RIZZI ${ }^{4}$, MAURICIO A. MOREIRA ${ }^{5}$, BERNARDO F. T. RUDORFF ${ }^{6}$, LEILA M. G. FONSECA ${ }^{7}$, ROGÉRIO T. FARIA ${ }^{8}$}

\begin{abstract}
RESUMO: Fotografias aéreas métricas atuais sobre áreas específicas nem sempre estão disponíveis. Esse é um dos principais problemas no Brasil para aplicação de técnicas de amostragem de área para a estimativa de safras. Este trabalho avaliou a técnica de fusão IHS aplicada em imagens Landsat7-ETM ${ }^{+}$para a substituição das fotografias aéreas de arquivo, em trabalhos de coleta de dados de campo e delimitação de elementos amostrais para os sistemas de estimativas de área de culturas agrícolas. As bandas 3; 4; 5 e 7 do sensor de $\mathrm{ETM}^{+}$foram usadas nas diferentes combinações de RGB e fundidas por IHS com a faixa pancromática para produzir imagens com melhor definição espacial. As imagens resultantes foram impressas na escala de 1:25.000 e usadas no trabalho de campo, em 85 elementos amostrais. As imagens fundidas permitiram identificar o uso e a cobertura do solo nos elementos amostrais. Conseqüentemente, as imagens fundidas de $\mathrm{ETM}^{+}$apresentaram grande potencial para o levantamento de dados de campo, para o mapeamento das características de uso e cobertura do solo e para as estimativas da área cultivada, baseadas em técnicas de amostragem da área.
\end{abstract}

PALAVRAS-CHAVE: amostragem, sensoriamento remoto, processamento de imagens.

\section{IMAGE FUSION THROUGH IHS TO IMPROVE IDENTIFICATION OF LAND USE IN SAMPLE ELEMENTS}

\begin{abstract}
Up-to-date metric aerial photographs covering specific areas are not always available. This is one of the main problems in Brazil when area sampling techniques for crop area estimation are used. This work aims to evaluate fused Landsat7-ETM ${ }^{+}$images for ground survey data collection and to identify and map land elements in order to replace the use of aerial photographs. The spectral bands 3; 4; 5 and 7 of the $\mathrm{ETM}^{+}$sensor were used in different RGB combinations merged with the panchromatic band 8 to produce images with better spatial resolution using IHS fusion technique. The resulting images were printed in a 1:25,000 scale and used during the ground survey campaign for 85 sampling units. Results pointed out that the fused images allowed identifying and mapping land elements in all the analyzed sampling units. Therefore, fused $\mathrm{ETM}^{+}$images presented a great potential for ground survey data collection and to identify and map land elements for crop area estimation based on area sampling techniques.
\end{abstract}

KEYWORDS: sampling, remote sensing, image processing.

\footnotetext{
${ }^{1}$ Trabalho aceito para publicação no XIII Simpósio Brasileiro de Sensoriamento Remoto.

${ }^{2}$ Economista, Doutorando em Sensoriamento Remoto, INPE, Av. dos Astronautas, 1.758, São José dos Campos - SP, Fone: (0XX12) 3945.6465, adami@dsr.inpe.br

${ }^{3}$ Eng $^{\mathrm{o}}$ Florestal, PhD, Instituto SIMEPAR, Curitiba - PR.

${ }^{4}$ Eng ${ }^{\mathrm{o}}$ Agrônomo, Doutor, UFPEL, Pelotas - RS.

${ }^{5}$ Eng ${ }^{\mathrm{o}}$ Agrônomo, Doutor, INPE, São José dos Campos - SP.

${ }^{6}$ Eng ${ }^{\mathrm{o}}$ Agrônomo, PhD, INPE, São José dos Campos - SP.

${ }^{7}$ Eng $^{\mathrm{a}}$ Eletrônica, Doutora, INPE, São José dos Campos - SP.

${ }^{8}$ Eng ${ }^{\text {o }}$ Agrônomo, Doutor, IAPAR, Londrina - PR.

Recebido pelo Conselho Editorial em: 5-3-2007
}

Aprovado pelo Conselho Editorial em: 17-7-2007 


\section{INTRODUÇÃO}

A estimativa de área plantada de culturas agrícolas por meio de amostragem de área pode utilizar três elementos para definir o local amostrado: pontos, polígonos irregulares e segmentos regulares (COCHRAN, 1977; THOMPSON, 2002). Após o sorteio das amostras, tais elementos são visitados em campo para inferir sobre as culturas agrícolas neles presentes. De posse dessa informação, estima-se a área ocupada pelas culturas em toda a região em estudo. Nesse caso, quanto mais eficiente e correta for a localização dos elementos amostrais no campo, bem como a quantificação da área das culturas neles contidas, melhor a qualidade das estimativas.

Os métodos de estimativa de áreas agrícolas por amostragem de área utilizam fotografias aéreas de arquivo para a localização dos elementos amostrais no campo, principalmente em função da alta resolução espacial. Entretanto, as fotografias aéreas atualmente disponíveis para esse fim foram, em geral, adquiridas há vários anos e, portanto, não representam mais a realidade de muitas feições existentes no campo. Isso dificulta enormemente a localização dos elementos amostrais (pontos, polígonos ou segmentos), bem como a identificação dos limites dos talhões das culturas presentes no seu interior. Além disto, a dinâmica temporal dos talhões agrícolas dificulta a correta estimativa da área no interior dos elementos amostrais.

Tal fato verificou-se no projeto denominado Pesquisa de Previsão e Acompanhamento de Safras (PREVS), conduzido pelo Instituto Brasileiro de Geografia e Estatística (IBGE), em parceria com o Instituto Nacional de Pesquisas Espaciais (INPE), em 1986. A PREVS utilizou fotografias aéreas obtidas em 1980, na escala de 1:25.000, para orientar os coletores de dados nos elementos amostrais no campo. Segundo COLLARES et al. (1993), a desatualização das fotografias e o alto custo de novos levantamentos aéreos foram alguns dos principais fatores que impossibilitaram a aplicação da metodologia proposta em todo o Brasil. A utilização de imagens dos satélites Ikonos, Quick Bird e SPOT-5, por exemplo, apesar de possuírem resolução espacial equivalente às fotografias aéreas, esbarram no alto custo de obtenção e na baixa freqüência de imageamento.

O uso de imagens de sensoriamento remoto de média resolução espacial, em substituição às fotografias aéreas de arquivo, pode facilitar a localização e a identificação in loco dos detalhes dos elementos amostrais (REZENDE, 2000). Tais imagens, além do custo relativamente reduzido, podem ser adquiridas em datas próximas ao trabalho de campo, em função do recobrimento sistemático e freqüente do globo terrestre pelos satélites. Para tanto, as imagens necessitam reunir características espaciais e espectrais de modo a permitir a localização dos elementos no campo. $\mathrm{O}$ sensor Enhanced Thematic Mapper plus $\left(\mathrm{ETM}^{+}\right)$, a bordo do satélite Landsat-7, operou, com sucesso, de abril de 1999 a maio de 2003. As imagens obtidas pelo $\mathrm{ETM}^{+}$possuem seis bandas espectrais centradas desde a região do visível até o infravermelho médio do espectro eletromagnético, com resolução espacial de $30 \mathrm{~m}$. Além disso, o sensor $\mathrm{ETM}^{+}$possui também uma banda pancromática com resolução espacial de $15 \mathrm{~m}$. Em comparação com os sensores de maior resolução espacial, como os existentes a bordo dos satélites Ikonos, Quick Bird e SPOT-5, por exemplo, o sensor $\mathrm{ETM}^{+}$apresenta como vantagem o menor custo e o recobrimento sistemático do globo terrestre, com a possibilidade de obtenção de uma imagem a cada 16 dias, da mesma área.

As técnicas de fusão permitem integrar a maior resolução espacial da banda pancromática à maior resolução espectral das demais bandas, produzindo imagem colorida que reúne ambas as características. As técnicas de fusão incluem: (i) Intensidade-Matiz-Saturação (IHS); (ii) Principais Componentes; (iii) Transformação de Brovey; (iv) Transformação Wavelet, dentre outros (CARPER et al., 1990; CHAVES et al., 1991; BLANC et al., 1998; POHL \& GENDEREN, 1998; NUNEZ et al., 1999). No entanto, o método de IHS é um dos mais utilizados, devido a sua eficiência e facilidade de implementação (TU et al., 2001).

Este trabalho teve como objetivo avaliar a técnica de fusão IHS aplicada em imagens do sensor Landsat $\mathrm{ETM}^{+}$para a substituição das fotografias aéreas de arquivo, em trabalhos de coleta de dados de campo e delimitação de elementos amostrais para os sistemas de estimativas de área de 
culturas agrícolas. No processo de fusão, várias composições coloridas foram também avaliadas em relação à caracterização dos elementos amostrais.

\section{MATERIAL E MÉTODOS}

O trabalho foi realizado em segmentos regulares de um painel amostral em região agropecuária no norte do Estado do Paraná, composta por 23 municípios pertencentes ao Núcleo Regional de Cornélio Procópio, da Secretaria de Estado da Agricultura e do Abastecimento do Paraná (SEAB). A área da região é de $7.480 \mathrm{~km}^{2}$ e está compreendida entre as seguintes coordenadas: $50^{\circ} 08^{\prime} 00^{\prime \prime} \mathrm{W}, 51^{\circ} 12$ ' $53^{\prime \prime} \mathrm{W}, 2^{\circ} 03^{\prime} 36^{\prime}$ 'S e $22^{\circ} 45^{\prime} 36^{\prime \prime} \mathrm{S}$.

As imagens Landsat $\mathrm{ETM}^{+}$, órbitas 221 e 222, ponto 76, adquiridas em 21 e 28-6-2002, respectivamente, foram processadas utilizando o "software" SPRING (CÂMARA et al., 1996). A localização dos segmentos foi realizada com auxílio de receptor GPS de navegação e do "software" Trackmaker (FERREIRA JÚNIOR, 2003).

Para aplicar a técnica de fusão de imagens IHS, foram utilizadas as bandas espectrais 3 (faixa do vermelho, de 0,63 a 0,69 $\mu \mathrm{m}$ ); 4 (na faixa do infravermelho próximo, de 0,78 a 0,90 $\mu \mathrm{m}$ ); 5 (na faixa do infravermelho médio, de 1,55 a 1,75 $\mu \mathrm{m}$ ), e 7 (na faixa do infravermelho médio, de 2,09 a $2,35 \mu \mathrm{m}$ ). Essas bandas apresentam resolução espacial de $30 \mathrm{~m}$. A banda pancromática (na faixa do visível e ao infravermelho próximo, de 0,52 a 0,90 $\mu \mathrm{m}$ ) também foi utilizada. Essa banda possui resolução espacial de $15 \mathrm{~m}$. As técnicas de correção atmosférica (CHAVEZ, 1988) e restauração de imagens (FONSECA, 1988) foram aplicadas para todas as bandas.

As técnicas de correção atmosférica consistem em minimizar os efeitos de absorção e espalhamento da energia eletromagnética gerados pelas partículas presentes na atmosfera. $\mathrm{O}$ modelo adotado para a correção atmosférica foi o proposto por CHAVEZ (1988), que é baseado na subtração do "pixel" escuro ou Dark Object Subtraction (DOS). O processo de restauração de imagens tem por objetivo reduzir o efeito de "borramento" de uma imagem, inserido pelo sensor, a partir do conhecimento a priori do fenômeno de degradação. Por meio de técnicas de restauração, é possível melhorar a qualidade da imagem degradada e também gerar imagens com maior resolução espacial efetiva em uma grade de amostragem mais fina (FONSECA, 1988); dessa forma, a banda Pancromática foi restaurada para $5 \mathrm{~m}$, e as demais bandas foram restauradas para $10 \mathrm{~m}$.

Em seguida, utilizou-se da técnica de fusão de imagens IHS, conforme descrito por SCHETSELAAR (1998), MATHER (1999), GONZALEZ \& WOODS (2000) e TU et al. (2001). A técnica consiste em realizar uma combinação de imagens no sistema de cores vermelho $(\mathrm{R})$, verde (G) e azul (B), para produzir as componentes: intensidade (I), que representa a energia total envolvida; matiz $(\mathrm{H})$, que representa a cor dominante ou a medida do comprimento de onda médio da luz que foi refletida ou transmitida, e saturação (S), que expressa o intervalo de comprimento de onda ao redor do comprimento de onda médio, no qual a energia é refletida ou transmitida. Com a obtenção dessas componentes, substitui-se a componente I pela imagem pancromática, de maior resolução espacial, no procedimento de retorno ao domínio RGB. Dessa maneira, a informação espectral da composição RGB é integrada à informação espacial da banda pancromática.

Nesse procedimento, foram usadas as seguintes combinações de bandas e cores: 4R5G3B; 5R4G3B e 4R5G7B. Para cada transformação IHS, igualaram-se a média e a variância da banda pancromática em relação à banda I, para uniformizar as informações das bandas a serem trocadas (GONZALES \& WOODS, 2000; TU et al., 2001). O uso de combinações RGB foi realizado em função de a área de estudo apresentar características heterogêneas quanto ao relevo, tipo de solo e outras condições, resultando em variações no comportamento espectral dos alvos. Desse modo, determinadas regiões têm seus atributos mais bem visualizados em certa combinação de cores RGB. Por outro lado, outras regiões ficam mais bem definidas em outra combinação. Toda a sequiência metodológica utilizada na geração das imagens fusionadas por IHS pode ser visualizada na Figura 1. 


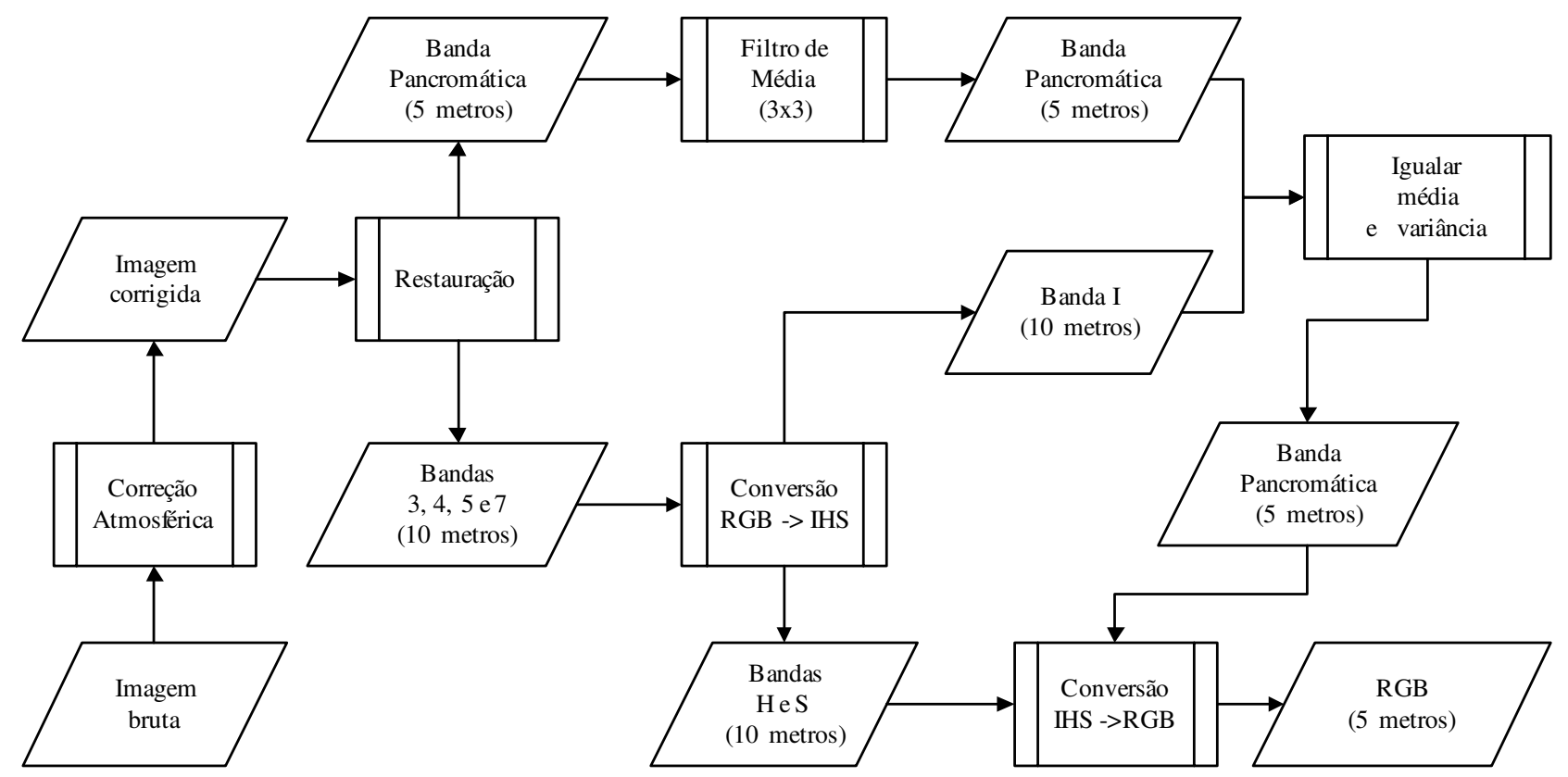

FIGURA 1. Metodologia utilizada na fusão IHS das imagens do sensor ETM+

O material de campo foi impresso na escala 1:25.000. Além das imagens IHS, foram impressas imagens nas mesmas composições RGB, utilizando-se das bandas espectrais originais do $\mathrm{ETM}^{+}(30 \mathrm{~m})$. Entretanto, em função da resolução espacial, tais imagens somente permitiram a impressão com boa qualidade visual na escala 1:50.000. Esse material foi utilizado para orientar a localização dos elementos e a coleta dos dados no campo, em 85 regiões, onde estavam contidos segmentos regulares com área de $1 \mathrm{~km}^{2}$, sorteados aleatoriamente, conforme descrito por ADAMI et al. (2005). Esses segmentos foram visitados de outubro a dezembro de 2002 para realizar a estimativa das áreas cultivadas com soja, milho e café. Em cada segmento, foram traçados sobre as imagens os polígonos correspondentes ao uso do solo no momento da visita, que posteriormente foram digitalizados para o cálculo da área. Dessa forma, as imagens impressas foram utilizadas tanto para facilitar a localização dos segmentos no campo, quanto para delimitar os talhões presentes no interior de cada segmento. Para título de comparação, todo o procedimento de coleta de informações em campo foi realizado, utilizando-se somente das fotografias aéreas de arquivo.

\section{RESULTADOS E DISCUSSÃO}

O procedimento de fusão de imagens por IHS possibilitou a impressão da documentação de campo em escala 1:25.000. Essa escala mostrou-se adequada para ser utilizada no trabalho de coleta de dados a campo, pois permitiu realçar características importantes da imagem, tais como estradas e feições de drenagem. Isso facilitou a localização e a delimitação dos talhões presentes no segmento. A Figura 2 está na escala utilizada para o trabalho de campo (1:25.000) e contém a imagem $\mathrm{ETM}^{+}$original $(30 \mathrm{~m})$ e a resultante do processo de fusão por IHS. Pode-se observar, na Figura 2, que houve substancial melhora na definição dos elementos da imagem híbrida (Figura 2 (b)) em relação à imagem original (Figura 2 (a)). A estrada (detalhe 1), as cristas de morros e os talvegues (detalhe 2) e as linhas de quebra-vento (detalhe 3) são exemplos do resultado obtido na melhoria da resolução espacial gerada pela fusão IHS (Figura 2 (b)), comparada à imagem original (Figura 2 (a)). Além disso, a fusão IHS ressaltou os contornos dos elementos sem perder essas características do produto na impressão em papel.

$\mathrm{Na}$ Figura 3, apresentam-se as variações de cores que ocorrem ao se realizar a fusão IHS nas diferentes combinações RGB utilizadas. O quadrado apresentado na Figura 3 é um dos elementos amostrais visitados, possui área de $1 \mathrm{~km}^{2}$ e representa os limites utilizados para realizar o levantamento. 

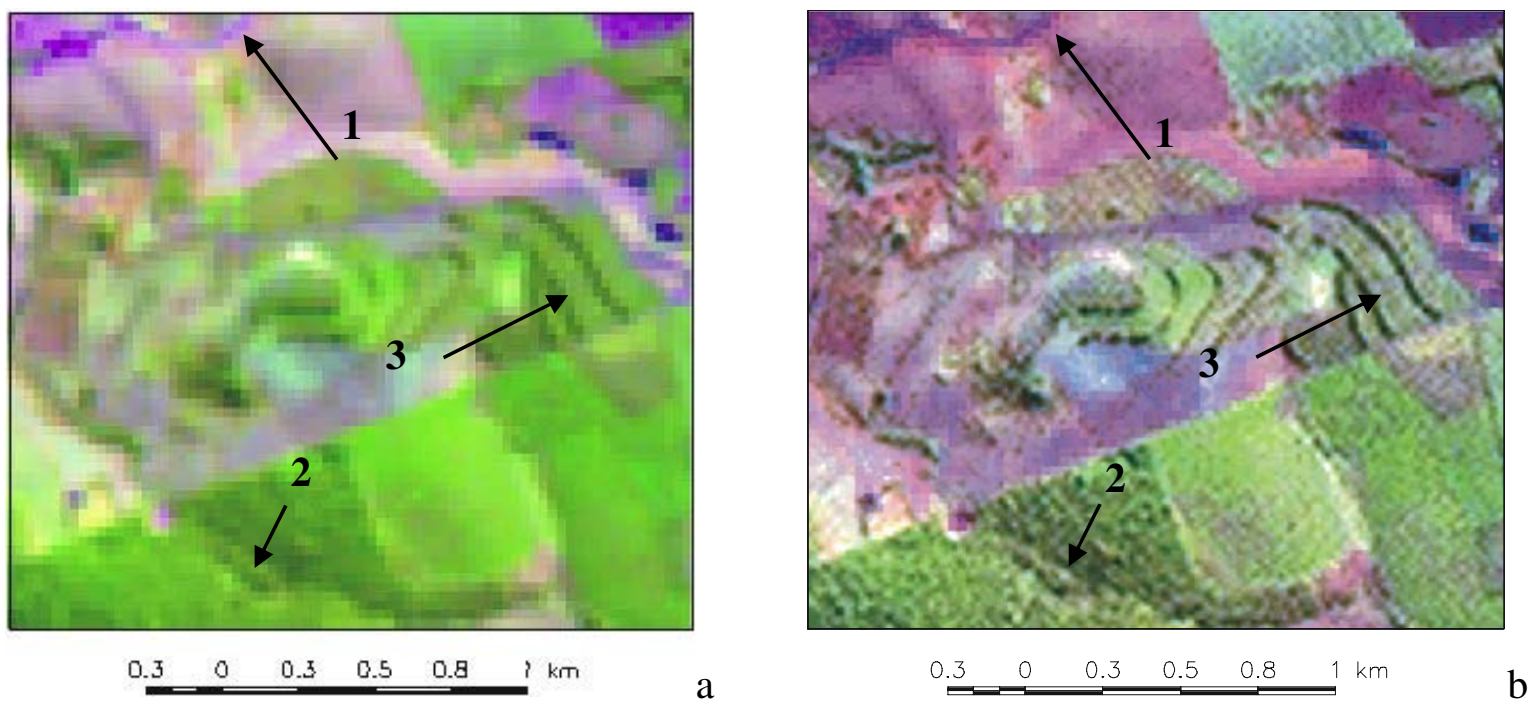

FIGURA 2. Imagem $\mathrm{ETM}^{+}$(a) 4R5G3B original $(30 \mathrm{~m})$ e (b) resultante da fusão IHS (5 m). As setas indicam: (1) estrada; (2) talvegue, e (3) quebra-vento.
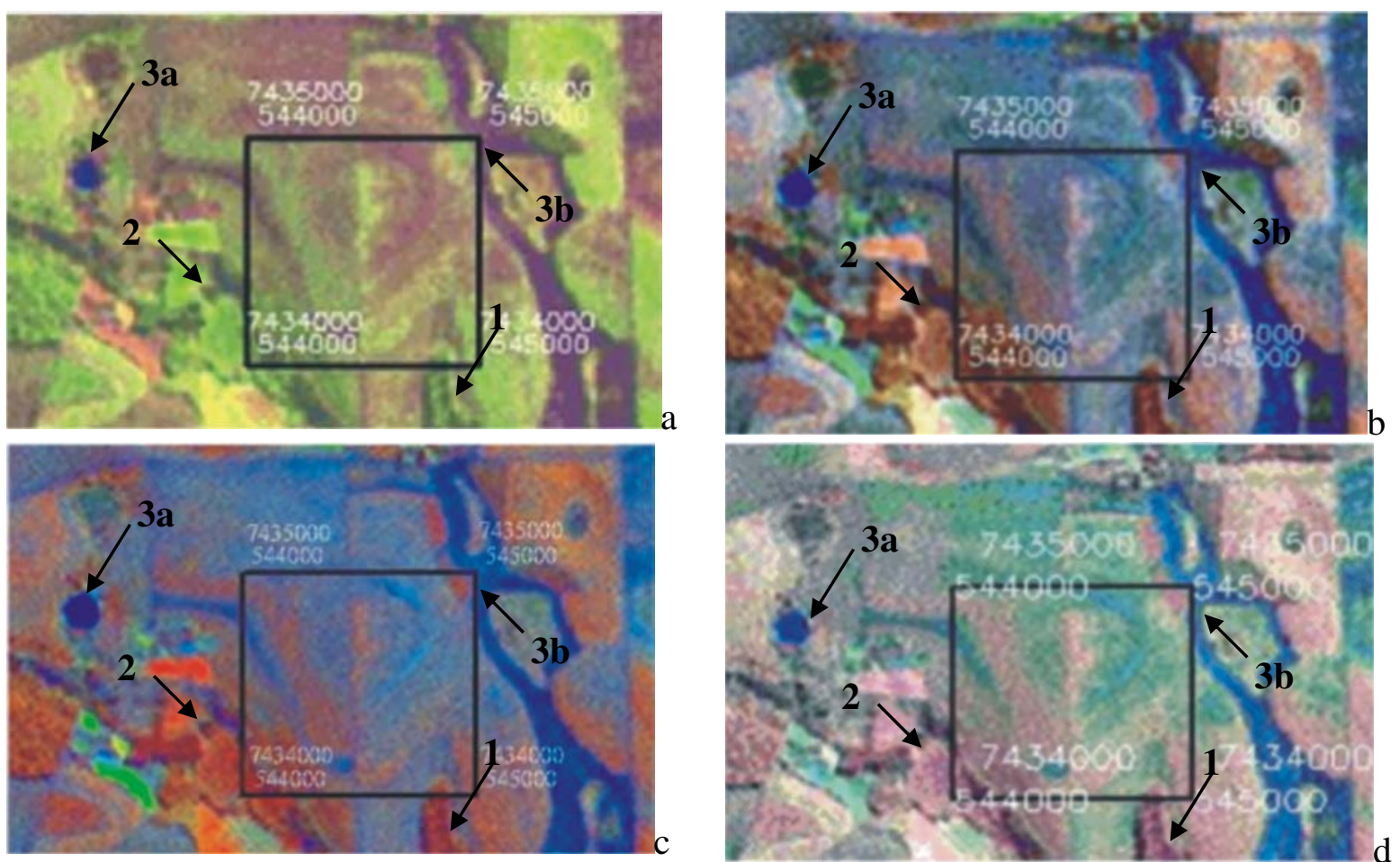

FIGURA 3. Fusão IHS para as combinações 5R4G3B (a), 4R5G7B (b), 4R5G3B (c) e 4R5G3B com fator de correção para saturação (d), bem como o segmento amostral visitado no campo.

Pela Figura 3, observa-se que as feições de vegetação ficam mais salientes nas combinações que possuem a banda 4 associada ao vermelho (Figuras 3 (b), (c) e (d)), vide detalhe 1. Essas combinações foram utilizadas para os elementos amostrais em que o contraste entre a vegetação e os outros componentes era necessário. Nota-se, também, que a imagem composta somente pelas bandas do infravermelho (4; 5 e 7) (Figura 3 b) descreve melhor as feições do relevo, facilitando a visualização das redes de drenagem, por exemplo (detalhe 2). Nesse caso, essa combinação foi utilizada para os elementos amostrais em que o relevo é parte importante da amostra. Essa combinação de bandas foi a que melhor permitiu a delimitação dos elementos apresentados por esta configuração de terreno. 
A composição 5R4G3B (Figura 3 a) dá destaque ao solo exposto e à água, enquanto, nas demais composições RGB, tais elementos são confundidos entre si. Isso pode ser verificado comparando-se o lago (detalhe 3a) com a área de solo exposto (detalhe 3b). Nas composições 4R5G7B (Figura 3 b), 4R5G3B (Figura 3 c) e 4R5G3B com fator de correção para saturação (Figura $3 \mathrm{~d}$ ), esses elementos (detalhes $3 \mathrm{a}$ e $3 \mathrm{~b}$ ) possuem, praticamente, a mesma cor, dificultando a sua identificação, o que não acontece na composição 5R4G3B (Figura 3 a). Da mesma maneira, essa combinação foi utilizada para identificar elementos amostrais em que o contraste entre solo exposto e água era necessário. Quando se compara a composição 4R5G3B com fator de correção para saturação (Figura $3 \mathrm{~d}$ ) com as demais, observa-se que a mesma não apresenta os efeitos de saturação apresentados pelas demais. Entretanto, esse procedimento diminui a intensidade das cores nas imagens, dificultando a diferenciação de alguns elementos, tais como áreas de mata e agricultura. Dessa forma, a composição 4R5G3B com fator de correção para saturação (Figura 3 d) só foi utilizada em casos específicos, nos quais as demais combinações apresentavam saturação excessiva, de modo a não permitir a identificação das feições presentes no interior do segmento amostrado. Esse resultado concorda com os obtidos por SCHETSELAAR (1998) e TU et al. (2001), que abordam a questão de que o método IHS não preserva as cores originais.

Um paralelo entre o resultado da fusão IHS nas imagens do sensor $\mathrm{ETM}^{+}$e as fotografias aéreas de arquivo é visualizado na Figura 4.
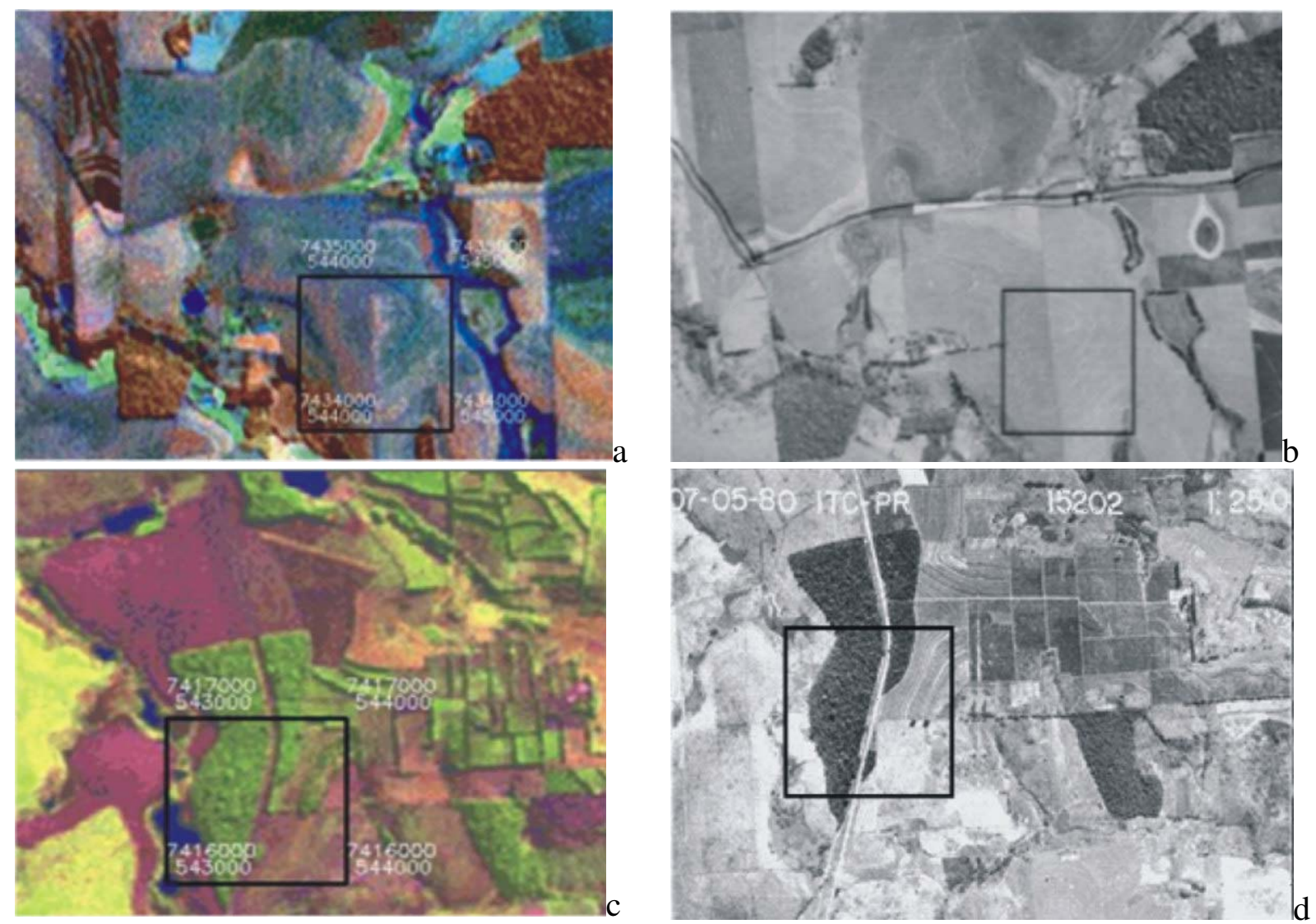

FIGURA 4. Imagens resultantes da fusão IHS (imagens coloridas) e das fotografias aéreas monocromáticas de arquivo.

Nas Figuras 4 a e 4 b, retratam-se áreas onde ocorreram mudanças entre a data de obtenção das fotografias em relação às imagens adquiridas pouco antes do trabalho de campo. Isso pode ser observado a partir da linha de árvores presente na fotografia aérea (Figura $4 \mathrm{~b}$ ), que margeia o segmento à direita, não mais presente na imagem do $\mathrm{ETM}^{+}$(Figura 4 a). Na imagem do $\mathrm{ETM}^{+}$ (Figura 4 a), observa-se um cafezal no quadrante superior esquerdo que não está presente na fotografia aérea (Figura $4 \mathrm{~b}$ ). A mata que se encontrava no quadrante inferior esquerdo da 
fotografia aérea (Figura 4 b) foi parcialmente removida, como pode ser constatado na Figura 4 (a). Na Figura 4 c, observa-se a presença de três lagos que estão no lado esquerdo do segmento, que não existiam na época de obtenção da fotografia aérea, em 1980 (Figura 4 d). As linhas de quebravento que aparecem na imagem do $\mathrm{ETM}^{+}$(Figura 4 c) não estão presentes na fotografia aérea (Figura $4 \mathrm{~d}$ ).

Apesar de as imagens geradas pela fusão IHS (Figura 4 - imagens coloridas) não possuírem a mesma resolução espacial da fotografia aérea (Figura 4 - imagens em preto e branco), os detalhes fornecidos pela cor e por ser uma imagem de data próxima ao trabalho de campo, ressaltam as mudanças ocorridas no período entre 1980 (época de obtenção das fotografias aéreas) e 2002 (época que foram obtidas as imagens Landsat). Conseqüentemente, ao ser realizado o trabalho de campo, mais detalhes da área de estudo poderão ser descritos com o uso da imagem do $\mathrm{ETM}^{+}$em relação à fotografia aérea, facilitando o trabalho de identificação dos elementos. Observa-se que, apesar da menor resolução espacial, as imagens $\mathrm{ETM}^{+}$forneceram informações condizentes com a realidade, facilitando a coleta de dados no campo (REZENDE, 2000).

Conforme apresentado, é importante que o material de campo facilite a delimitação dos elementos encontrados no momento da visita. Quanto mais próximas forem as datas de trabalho de campo e de aquisição da imagem, melhor será o resultado da delimitação dos talhões.

\section{CONCLUSÕES}

Para a caracterização dos elementos amostrais em campo, nos estudos de estimativa de áreas de culturas agrícolas por meio de amostragem por área, as imagens resultantes da técnica de fusão IHS (ETM+) mostraram ser adequadas para substituir as fotografias aéreas de arquivo. Considerando as composições coloridas, pode-se concluir que, em função do relevo acidentado, a composição colorida recomendada é a que combina as bandas fusionadas 4R5G7B. Para as regiões com presença de corpos d'água, a composição que melhor identifica as feições é a composição 5R4G3B. Finalmente, para a caracterização dos elementos amostrais que apresentam maior variabilidade de vegetação, a composição 4R5G3B é a mais indicada.

\section{AGRADECIMENTOS}

À Secretaria de Estado do Meio Ambiente do Paraná (SEMA), por fornecer as fotografias aéreas de arquivo, e à Secretaria de Estado da Agricultura e do Abastecimento do Paraná (SEAB), pelo suporte durante o trabalho de campo.

\section{REFERÊNCIAS}

ADAMI, M.; MOREIRA, M.A.; RUDORFF, B.F.T.; FREITAS, C.C.; FARIA, R.T. Expansão direta na estimativa de culturas agrícolas por meio de segmentos regulares. Revista Brasileira de Cartografia, Presidente Prudente, v.1, n.57, p.22-7, 2005.

BLANC, P.; BLUS, T.; RANCHIN, T.; WALD, L.; ALOISI, R. Using interated rational filter banks within the ARSIS concepts for producing $10 \mathrm{~m}$ Landsat multispectral images. International Journal of Remote Sensing, Basingstoke, v.19, n.12, p.2.331-43, 1998.

CÂMARA, G.; SOUZA, R.C.M.; FREITAS, U.M.; GARRIDO, J.C.P. SPRING: Integrating Remote Sensing and GIS with Object-Oriented Data Modelling. Computers and Graphics, New York, v.20, n.3, p.395-403, 1996.

CARPER, W.J.; LILLESAND, T.M.; KIEFER, R.W. The use of intensity-hue-saturation transformations for merging SPOT panchromatic and multispectral image data. Photogrammetric Engineering and Remote Sensing, Falls Church, v.56, n.4, p.459-67, 1990.

CHAVES, P.S.; SIDES, S.C.; ANDERSON, J.A. Comparison of three difference methods to merge multi resolution and multispectral data: Landsat TM and SPOT panchromatic.

Photogrammetric Engineering and Remote Sensing, Falls Church, v.57, n.3, p.295-303, 1991. 
CHAVEZ, P.S. An improved dark-object subtraction techique for atmospheric scattering correction of multispectral data. Remote Sensing of Environment, New York, v.24, n.3, p.459- 79, 1988.

COCHRAN, W.G. Técnicas de amostragem. 2.ed. Rio de Janeiro: Fundo de Cultura, 1977. 555 p.

COLLARES, J.E.R.; LAURIA, C.A.; CARRILHO, M.M. Pesquisa de previsão e acompanhamento de safras baseada em painéis de amostras de áreas. In: SIMPÓSIO BRASILEIRO DE

SENSORIAMENTO REMOTO, 7., 1993, Curitiba. Anais... Curitiba: INPE, 1993. v.4, p.450-3.

FERREIRA JÚNIOR, O. O GPS TRACKMACKER. Disponível em:

$<$ http://www.GPStm.com/port/>. Acesso em: Fev. 2003.

FONSECA, L.M.G. Restauração de imagens do satélite Landsat por meio de técnicas de projeto de filtros FIR. 1988. 148 f. Dissertação (Mestrado em Engenharia Eletrônica) - Instituto Tecnológico de Aeronáutica, São José dos Campos, 1988.

GONZALEZ, R.C.; WOODS, R.E. Processamento de imagens digitais. São Paulo: Ed. Edgard Blücher, 2000. 509 p.

NUNEZ, J.; XAVIER, O.; OCTAVI, F.; ALBERT, P.; VICENC, P.; ROMAN, A. Multiresolution - based imaged fusion with additive wavelet decomposition. IEEE Transaction Geoscience Remote Sensing, New York, v.37, n.3, p.1.204-11, 1999.

MATHER, P.M. Computer processing of remotely-sensed images: an introduction. Chichester: John Wiley \& Sons, 1999. 292 p.

POHL, C.; GENDEREN, J.L. Van. Multisensor image fusion in remote sensing: concepts, methods and applications. International Journal of Remote Sensing, Basingstoke, v.19, n.4, p.823-54, 1998.

REZENDE, A.C.P. Técnicas de geoprocessamento e sensoriamento remoto aplicadas ao Sistema Brasileiro de Previsão de Safras. 2000.98 f. Dissertação (Mestrado em Sensoriamento Remoto) Instituto Nacional de Pesquisas Espaciais, São José dos Campos, 2000.

SCHETSELAAR, E.M. Fusion by the IHS transform: should we use cylindrical or spherical coordinates? International Journal of Remote Sensing, Basingstoke, v.19, n.4, p.759-65, 1998.

THOMPSON, S.K. Sampling. 2.ed. New York: John Wiley \& Sons, 2002. 343 p.

TU, T.; SU, S.; SHYU, H.; HUANG, P.S. Efficient intensity-hue-saturation-based image fusion with saturation compensation. Optical Engineering, Redondo Beach, v.40, n.5, p.720-8, 2001. 